\title{
Ureteritis por citomegalovirus en receptor de trasplante renal. Informe de un caso con presentación inusual
}

\author{
Rico JE*, Cardona X*, Rodelo J*, Reino A, Arias LF**, Arbeláez $\mathrm{M}^{*}$. \\ *Sección de Nefrología y Grupo de Trasplante Renal. Universidad de Antioquía, Hospital Universitario San \\ Vicente de Paúl, Medillín, Colombia. **Departamento de Patología. Facultad de Medicina. Universidad de \\ Antioquía, Grupo PRYT, Medellín, Colombia.
}

Actas Urol Esp. 2008;32(6):649-652

\begin{abstract}
RESUMEN
URETERITIS POR CITOMEGALOVIRUS EN RECEPTOR DE TRASPLANTE RENAL. INFORME DE UN CASO CON PRESENTACIÓN INUSUAL

La infección por citomegalovirus (CMV) es la infección viral más frecuente en pacientes trasplantados, pero es muy inusual el compromiso del tracto urinario. Sólo se han informado unos pocos casos de uretritis por CMV en trasplantados renales. En los informes previos la presentación clínica más habitual es nefropatía obstructiva, a menudo en ausencia de enfermedad sistémica, o, algunas veces, puede simular un episodio de rechazo con mínimos síntomas obstructivos. Nosotros describimos un caso más de uretritis por CMV en un paciente trasplantado renal con ureterostomía y una presentación muy inusual caracterizada por síntomas de infección de vías urinarias y ulceración en la boca de la ureterostomía. El número incrementado de informes de ureteritis por CMV en trasplantados renales plantea la posibilidad de un aumento en la incidencia de esta complicación post-trasplante.
\end{abstract}

Palabras clave: Citomegalovirus. Trasplante renal. Ureteritis. Inmunosupresión.

\begin{abstract}
URETEROSTOMY CYTOMEGALOVIRUS INFECTION PRESENTING AS STOMA ULCERATION IN A KIDNEY ALLOGRAFT RECEPTOR: A CASE REPORT

Cytomegalovirus (CMV) is the most common viral infection affecting transplant patients, but urinary tract involvement has been rare. Only a few cases of symptomatic ureteritis have been reported in renal transplant recipients. In previous reports the presentation of CMV ureteritis is obstructive nephropathy, often in the absence of systemic illness, or rarely it may also mimic allograft rejection with minimal obstructive symptoms. We describe an additional case of CMV ureteritis in a patient with cutaneous ureterostomy. The unusual clinical presentation with urinary infection symptoms and ureterostomy stoma ulceration constitute a very particular presentation. The increasing report cases with CMV ureteritis suggest an increase of this post-transplant complication.
\end{abstract}

Keywords: Cytomegalovirus. Kidney transplantation. Ureteritis. Immunosuppression.

$\mathrm{L}$ as infecciones continúan siendo una importante causa de morbilidad y mortalidad en trasplantes de órganos sólidos, a pesar de la mejoría en las técnicas quirúrgicas, regímenes de inmunosupresión menos deletéreos y tratamientos profilácticos ${ }^{1,2}$. La infección y enfermedad por citomegalovirus (CMV) son frecuentes en receptores de trasplante renal. Después de la infección primaria el virus persiste indefinidamente, en forma latente, en varios tejidos (riñón, hígado, pulmones y otros). Típicamente, la enfermedad por CMV ocurre en los primeros 6 meses pos-trasplante renal, con un pico de máxima incidencia entre el segundo y cuarto $\operatorname{mes}^{1,2,3}$, y se caracteriza por la presencia de signos y sintomas sistémicos. Sin embargo hay casos informados de presentaciones atípicas y tardías de la infección por 
$\mathrm{CMV}^{4}$. Existen pocos informes de ureteritis por CMV en receptores de trasplante renal, que suelen presentarse como obstrucción ureteral y/o disfunción del injerto renal y que podrían estar emergiendo como una complicación cada vez más frecuente ${ }^{5-11}$.

Nosotros presentamos el caso de un paciente receptor de trasplante renal con ureterostomía cutánea, quien presentó enfermedad por CMV localizada en el sitio de la ureterostomía, asociada a viremia negativa. Lo inusual de este caso y el aparente aumento en el número de casos publicados en los últimos 10 años plantea la posibilidad de un incremento de esta complicación pos-trasplante renal.

\section{CASO CLÍNICO}

Paciente de sexo masculino, de 29 años de edad, con antecedente de valvas uretrales posteriores en la infancia, las cuales se corrigieron quirúrgicamente. El paciente desarrolló, posteriormente a la cirugía, uropatía obstructiva por estenosis uretral severa, hidronefrosis bilateral e insuficiencia renal crónica terminal. Inicia hemodiálisis en el año 2003 e ingresa, meses después, en lista de espera para trasplante. En el protocolo pre-trasplante se decide la realización de ureterostomía cutánea por disfunción vesical severa asociada a la estenosis crítica uretral. El paciente tiene historia de $\operatorname{IgG}(+)$ para CMV y se le hace trasplante renal de donante cadavérico, IgG CMV (+), en junio del 2006. Recibe terapia de inducción con timoglobulina por historia de anticuerpos citotóxicos positivos, y esquema de mantenimiento inmunosupresor con prednisolona, micofenolato mofetil y ciclosporina. Se le deja profilaxis con valganciclovir por 3 meses porque recibió timoglobulina (protocolo). Se le realiza ureterostomía cutánea sin complicaciones.

A los 15 días pos-trasplante presenta elevación súbita de la creatinina, hasta $2,2 \mathrm{mg} / \mathrm{dL}$, por lo que se realiza biopsia del injerto, la cual confirma un rechazo celular agudo tipo 1A según el esquema de Banff, por lo que recibe pulsos de metilprednisolona y se cambia esquema de inmunosupresión de ciclosporina a tacrolimus. En los siguientes dos meses, el paciente presenta dos episodios de infecciones urinarias (bacterianas) por lo que es hospitalizado y manejado con tratamiento antibiótico. Se suspende el valganciclovir a los tres meses que es el tiempo de profilaxis en nuestro protocolo. En octubre de 2006 el paciente nuevamente presenta síndrome febril, astenia, adinamia, orina fétida y en la boca de la ureterostomía cutánea presenta lesiones blanquecinas que cubren toda su superficie, asociadas a signos inflamatorios locales (Fig. 1) sugestivas de infección micótica.

En los exámenes paraclínicos se encuentra anemia y leucopenia: Hematocrito: 35\%, hemoglobina $11,8 \mathrm{~g} / \mathrm{dL}$; leucocitos $3.000 / \mathrm{mm}^{3}$, linfocitos $60 \%$, neutrófilos $28 \%$, plaquetas $152.000 / \mathrm{mm}^{3}$, proteína C reactiva: $15 \mathrm{mg} / \mathrm{dL}$, creatinina sérica: $2,5 \mathrm{mg} / \mathrm{dL}$; urocultivo positivo para Pseudomona auriginosa. Hemocultivos negativos y carga viral (PCR) para CMV negativa. Recibe tratamiento con meropenen y fluconazol.

Luego de 8 días de tratamiento continúa sin mejoría de las lesiones en la boca de la ureterostomía y con picos febriles, se decide toma de biopsia de estas lesiones. En el estudio microscópico se demuestra la presencia de abundantes inclusiones citopáticas de tipo CMV en células endoteliales del tejido de granulación de la úlcera; el diagnóstico fue confirmado por inmunohistoquímica (Fig. 2). Se repite la carga viral para CMV la cual es nuevamente negativa. El Paciente recibe tratamiento con ganciclovir intravenoso por 14 días y luego se continúa con valganciclovir hasta la fecha actual. Las lesiones en la ureterostomía empiezan a mejorar a los 6 días de tratamiento y a las tres semanas han desaparecido (Fig. 1). Actualmente el paciente está mejor, con función renal subóptima (creatinina sérica 1,8 ) y sin lesiones en la ureterostomía.
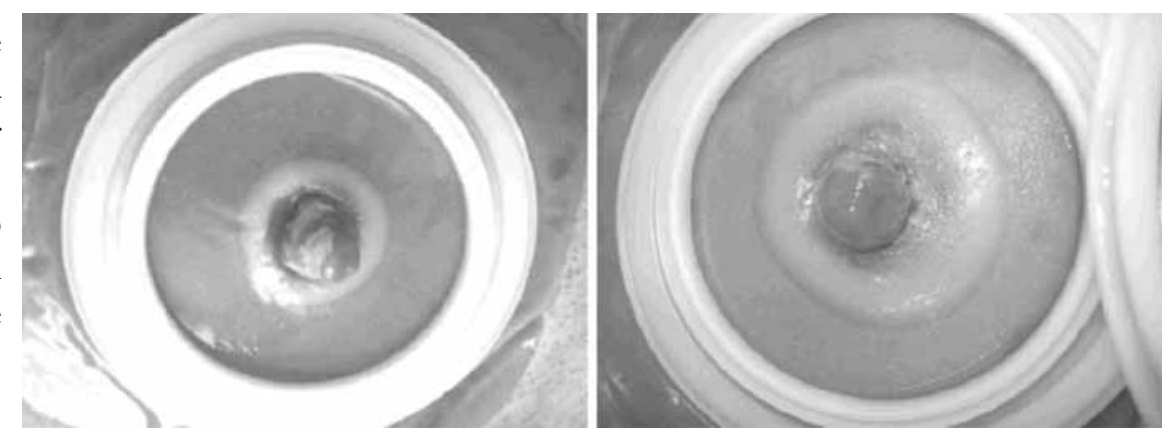

FIGURA 1. Boca de ureterostomía cutánea; a la izquierda se observa la lesión blanquecina, con membranas en su superficie; histológicamente se observó extensa ulceración con tejido de granulación e inclusiones citomegálicas. Derecha, imagen de la boca de ureterostomía tres semanas después del inicio del tratamiento antiviral. Las lesiones membranosas casi han desaparecido. 


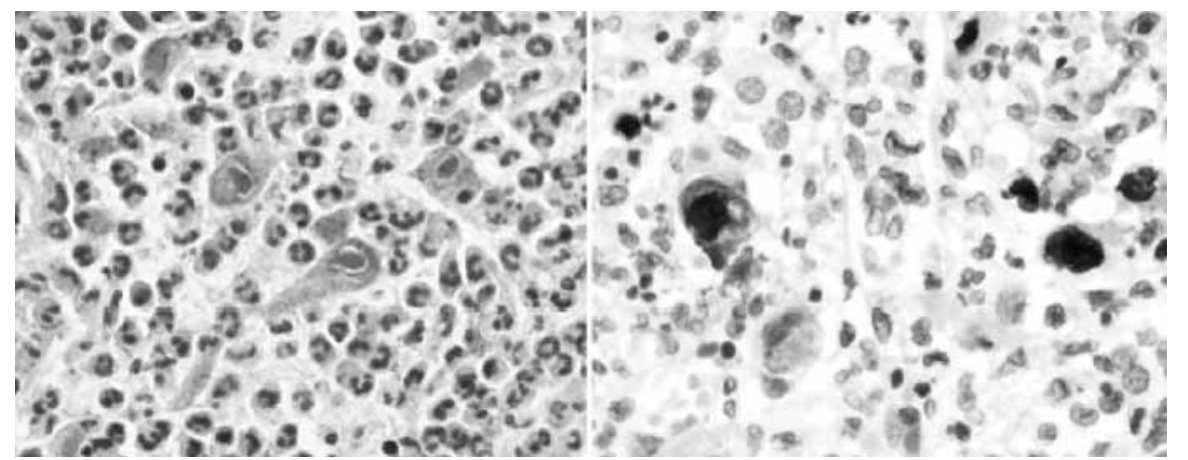

FIGURA 2. Izquierda: Imagen microscópica a gran aumento en la que se observan, en el centro de la imagen, tres células grandes (citomegalia) con inclusiones intranucleares con halo claro a su alrededor, caracteristicas de la infección por citomegalovirus; también se identificaron inclusiones citoplasmáticas (H\&E, aumento original, X400). Derecha: Inmunohistoquimica para CMV en la que se demuestran múltiples células positivas para antigenos del virus (inmunohistoquímica para CMV, aumento original, X400).

\section{DISCUSION}

Los injertos renales pueden ser un sitio frecuente de infección subclínica por CMV, especialmente después de episodios de rechazo agudo y uso de terapia depletiva linfocítica (timoglobulina, antiCD3), sin embargo, las inclusiones virales se observan en menos del $1 \%$ de las biopsias renales ${ }^{12}$. Hay publicados muy pocos casos de ureteritis por CMV en receptores de trasplante renal ${ }^{5-11}$. En varios de estos informes la ureteritis por CMV es causa de obstrucción ureteral, concluyendo los autores que ésta es una de las causas poco comunes de uropatía obstructiva del riñón trasplantado. Sin embargo, nuestro paciente es un caso diferente, ya que no se presentó como uropatía obstructiva y tenía ureterostomía cutánea, sitio en el cual se detectó la reactivación viral. El paciente tenía factores de riesgo para enfermedad por CMV: uso de timoglobulina y presencia previa de rechazo agudo tratado con corticoides.

La infección por CMV es la infección oportunista más frecuente en trasplantados de órganos sólidos. La infección sintomática suele ocurrir durante el período de máxima inmunosupresión (1-4 meses posteriores al trasplante) ${ }^{2,13}$. La presentación clínica habitualmente incluye fiebre, leucopenia o compromiso de órganos; la presentación más común de la enfermedad por CMV es un síndrome similar a la mononucleosis, con fiebre, malestar, mialgias $\mathrm{y}$ artralgias, usualmente asociadas a leucopenia, linfocitosis atípica leve y en ocasiones trombocitopenia $^{2}$. Las manifestaciones clínicas de la enfermedad pueden deberse a efectos directos causados por el virus y/o a efectos indirectos producidos por liberación de citoquinas en respuesta a la replicación vi$\mathrm{ral}^{13,14}$. La infección y replicación viral pueden llevar a lesión crónica del injerto y a rechazo ${ }^{15}$. La presentación más común de la ureteritis por CMV, en la revisión de la literatura, es estenosis ureteral ${ }^{5-11}$, es posible que la respuesta inflamatoria local y los cambios citopáticos lleven a ulceración y necrosis, con subsiguiente cicatrización y fibrosis que produciría estenosis. Un posible mecanismo que facilitaría la replicación viral en uréteres podría ser la isquemia u otras lesiones inflamatorias, que resultarian en alteraciones que harían más probable la replicación del virus ${ }^{6}$, sin embargo, este mecanismo "facilitador" de la replicación no ha sido demostrado.

De otro lado, en nuestro caso la carga viral, antes y después del diagnóstico histológico, fue negativa (no demostrando el número de copias considerado positivo para replicación: valor de corte 600 copias $/ \mathrm{mL}$ ); este hallazgo plantea dos posibilidades, primera: sabemos que la PCR en tiempo real, para detectar ADN del CMV no es 100\% sensible; segunda: es posible que la reactivación local de la infección y la replicación localizada en la mucosa del uréter no genere elevación significativa, detectable por la técnica, del número "umbral" de copias del ADN viral.

\section{IMPLICACIONES CLÍNICAS}

La ureteritis por CMV es una presentación atípica poco frecuente de la enfermedad por CMV. En la mayoría de casos informados en la literatura se asocia con estenosis ureteral. En pacientes con ureterostomía cutánea que presenten lesiones que macroscópicamente parezcan ocasionadas por hongos, no olvidar que el CMV puede ser la causa de ésta, aun teniendo carga viral para CMV negativa. Por lo tanto, el diagnostico definitivo muchas veces lo confirmará el estudio histológico. Esta complicación del trasplante renal podría estar aumentando en los últimos años. 


\section{Agradecimientos}

Les agradecemos a los Doctores Gonzalo Mejía, José N. Carvajal, Jorge Henao, Jorge L. Arango y Álvaro García, por su participación en el análisis de este caso clínico.

\section{REFERENCIAS}

1. Caring for Australians with Renal Impairment (CARI). The CARI guidelines. CMV disease and kidney transplant: diagnostic tests for cytomegalovirus in renal transplantation. Nephrology (Carlton). 2004;9(Suppl 3):S23-S26.

2. Fishman JA, Rubin RH. Infection in organ-transplant recipients. N Engl J Med 1998;338(24):1741-1751.

3. Singh N. Cytomegalovirus infection in solid organ transplant recipients: new challenges and their implications for preventive strategies. J Clin Virol. 2006;35(4):474-477.

4. Slifkin M, Tempesti P, Poutsiaka DD, Snydman DR. Late and Atypical Cytomegalovirus Disease in Solid-Organ Transplant Recipients. Clin Infect Dis. 2001;33(7):E62-E68

5. Lowell JA, Stratta RJ, Morton JJ, Kolbeck PC, Taylor RJ. Invasive cytomegalovirus infection in a renal transplant ureter after combined pancreas-kidney transplantation: an unusual cause of renal allograft dysfunction. J Urol. 1994;152(5Pt1): 1546-1548.

6. Thomas MC, Russ GR, Mathew TH, Rao Mohan M, Cooper J, Walker RJ. Four cases of CMV ureteritis: emergence of a new pattern of disease?. Clin Transplant 2001:15(5):354-358.

7. Leikis MJ, Denford AJ, Pidgeon GB, Hatfield PJ. Post-renal transplant obstruction caused by cytomegalovirus ureteritis. Nephrol Dial Transplant. 2000;15(12):2063-2064.

8. Dulcloux D, Bresson-Vautrin C, Chalopin JM. Is CMV the cause of ureteral stricture in renal transplantation recipients? Transplant Int 1997;10(3):238-240.
9. Moudgil A, Germain BM, Nast CC, Toyoda M, Strauss FG, Jordan SC. Ureteritis and cholecystitis two unusual manifestations of cytomegalovirus disease in renal transplant recipients. Transplantation. 1997;64(7):1071-1073.

10. Peretti N, Said MH, Bouvier R, Koch-Nogueira PC, Thouvenot $\mathrm{D}$, Martin X et al. Cytomegalovirus infection may cause ureteral necrosis. Transplantation. 2000;69(4):670-671.

11. Vongwiwatana A, Vareesangthip K, Vasuvattakul S, Prommol S, Nualyong C, Parichatikanond $\mathrm{P}$, et al. Ureteritis due to cytomegalovirus infection in renal transplant recipient: a case report. Tranasplant Proc. 2000;32(7):1927.

12. Kashyap R, Shapiro R, Jordan M, Randhawa PS. The clinical significance of cytomegaloviral inclusions in the allograft kidney. Transplantation. 1999;67(1):98-103.

13. Rubin RH, Colvin RB. Impact of cytomegalovirus infection on renal transplantation. In: Racusen LC, Solez K, Burdick JF, eds. Kidney Transplant Rejection. New York, Marcel Dekker; 1998, pp 605-626.

14. Nett PC, Heisey DM, Fernandez LA, Sollinger HW, Pirsch JD. Association of cytomegalovirus disease and acute rejection with graft loss in kidney transplantation. Transplantation. 2004 Oct 15;78(7):1036-1041.

15. Sagedal S, Hartmann A, Nordal KP, Osnes K, Leivestad T, Foss A et al. Impact of early cytomegalovirus infection and disease on long-term recipient and kidney graft survival.Kidney Int. 2004 Jul;66(1):329-37.

Correspondencia autor: Dr. J.E. Rico Fontalvo

Sección de Nefrología. Hospital Universitario San Vicente de Paúl Carrera, $64 \mathrm{~N}^{\circ}$ 51-70. Te.: (+57) 42128787

E-mail autor: jorgericof@yahoo.com

Información artículo: Nota Clínica

Trabajo recibido: abril 2007

Trabajo aceptado: julio 2007 